\title{
Hydrothermally synthesized nanocrystalline tin disulphide as visible light-active photocatalyst: Spectral response and stability
}

Raquel Lucena, Fernando Fresno, José C. Conesa*

Instituto de Catálisis y Petroleoquímica, CSIC

Campus de Excelencia UAM-CSIC

Marie Curie 2, Cantoblanco

28049 Madrid, Spain

Keywords: $\mathrm{SnS}_{2}$, Photocatalysis, Visible light, Spectral response, Stability

\begin{abstract}
A simple hydrothermal method is implemented for the synthesis of $\mathrm{SnS}_{2}$ nanoparticles, using non expensive $\mathrm{SnCl}_{4} \cdot 5 \mathrm{H}_{2} \mathrm{O}$ and thiourea as reactants. The photocatalytic properties of the synthesized material under visible light irradiation are evaluated examining the degradation of formic acid in an aqueous solution containing the solid in suspension, using eventually band-pass filters to verify the dependence of photoactivity on light wavelength. The results demonstrate that the material has high visible light photocatalytic activity with an action spectrum covering the full spectral range absorbed by the solid (up to ca. $600 \mathrm{~nm}$ ), and that the latter is also more photoactive and resistant to photocorrosion than the more toxic but frequently used CdS. Tin disulphide, containing only abundant and nontoxic elements, is thus suggested as advantageous alternative for solar light use.
\end{abstract}

\section{Introduction}

$\mathrm{TiO}_{2}$, particularly in the anatase form, is by far the most studied and used photocatalyst, in view of its low cost, high activity, chemical and photochemical stability, and biocompatibility [1]. However it only responds to UV light due to its wide bandgap (3.2 eV), being unable to use visible light $(\lambda>400 \mathrm{~nm})$ which is the main component in the solar spectrum [2]. Recently there has been an increasing interest in the photocatalytic application of semiconductors which are able to absorb visible light: apart from sensitized systems, $\mathrm{TiO}_{2}$ doped with electropositive (e.g. $\mathrm{Sn}, \mathrm{V}, \mathrm{Fe}, \mathrm{Cr}, \mathrm{W}$ or $\mathrm{Pt})$ and electronegative $(\mathrm{N}, \mathrm{C}, \mathrm{S})$ elements [3], some binary transition metal oxides $\left(\mathrm{WO}_{3}, \mathrm{Bi}_{2} \mathrm{O}_{3}, \mathrm{Fe}_{2} \mathrm{O}_{3}[4]\right.$ or $\mathrm{Cu}_{2} \mathrm{O}$ 
[5,6]), mixed oxides that include main group elements like $\mathrm{BiVO}_{4}$ [7], $\mathrm{Sn}_{2} \mathrm{Nb}_{2} \mathrm{O}_{7}$ [8] or $\operatorname{lnTaO}_{4}$ [9], nitrides and oxynitrides like $\mathrm{Ta}_{3} \mathrm{~N}_{5}$ [10], $\mathrm{LaTiO}_{2} \mathrm{~N}$ [11] or $\mathrm{ZnO}: \mathrm{GaN}$ solid solutions [12] and sulphides like CdS [13], $\mathrm{MoS}_{2}$ [14], $\mathrm{Bi}_{2} \mathrm{~S}_{3}$ [15], $\ln _{2} S_{3}[16,17]$ and derivatives of them have been proposed. Among these sulphides CdS is currently the most studied one $[18,19]$, but this compound is detrimental to human health and the environment due to its high toxicity.

Here we present data on the behaviour of $\mathrm{SnS}_{2}$ as photocatalyst able to use visible light. $\mathrm{SnS}_{2}$ has a $\mathrm{Cdl}_{2}$-type crystal structure [20] consisting in two layers of hexagonally packed sulphur anions with sandwiched tin cations which are octahedrally coordinated by six neighbour sulphur atoms; these S-Sn-S trilayers are stacked over one another, being weakly bonded by Van der Waals interactions. Several polytypes of this compound exist [21] due to the possibility of different layer stacking sequences; the most stable of them, the $2 \mathrm{H}$ polytype, which has also the simplest structure, has a bandgap $E_{g}=2.2 \mathrm{eV}$ [22], the other ones having very similar $E_{g}$ values around 2.2-2.4 eV [23-25].

$\mathrm{SnS}_{2}$ has interesting electrical, optical and gas sensing properties [26-28]; owing to its photoconductivity it is also regarded as a prospective candidate for use in solar cells and opto-electronic devices $[25,29]$. Studies on the properties of $\mathrm{SnS}_{2}$ as standalone photocatalyst are scarce [30-32], and only in the first of these it has been proved that the system has activity with visible light (i.e. in conditions excluding UV components); but the spectral range in which photocatalysis occurs on $\mathrm{SnS}_{2}$ has not been verified until now. In other cases photocatalysis has been studied for $\mathrm{SnS}_{2}$ in combination with $\mathrm{TiO}_{2}[33,34]$ or $\mathrm{SnO}_{2}$ [35] from a sensitizing perspective. It must be noted here that the substance being degraded photocatalytically in all these studies was always a dye able to absorb visible light, so that there could be doubt whether it was the dye or the semiconductor who was excited in first place, especially since there was no study on the spectral dependence of this effect to check whether it was similar to the absorption spectrum of the dye or to that of the solid. Also, the resistance to corrosion of the sulphide under photooxidation conditions has been only scarcely examined [30]. Finally it may be mentioned that there are a few studies examining the photoelectrochemical behaviour of $\mathrm{SnS}_{2}$ in aqueous or organic media [36-38].

Here we present a detailed study of the spectral response of $\mathrm{SnS}_{2}$ in a simple photocatalytic reaction, the mineralization of formic acid, carried out with visible light. Using this substrate, which only absorbs light in the hard UV range, one is sure that the absorption of light by the reactant plays no role in the process. The photo- catalytic activity of $\mathrm{SnS}_{2}$ in this reaction is found to be high in the whole wavelength range of its bandgap absorption; furthermore, the results indicate that this compound is significantly more active and stable than $\mathrm{CdS}$, which as said above is the sulphide most widely studied for photocatalysis.

\section{Experimental}

\subsection{Synthesis and characterization of the photocatalyst}

$\mathrm{SnS}_{2}$ was synthesized hydrothermally in a $125 \mathrm{~mL}$ Teflon-lined stainless steel autoclave, using as starting reagents $1.56 \mathrm{mmol}$ of $\mathrm{SnCl}_{4} \cdot 5 \mathrm{H}_{2} \mathrm{O}$ (Aldrich 98\%) and $6.25 \mathrm{mmol}$ of thiourea (Aldrich 99\%) dissolved in $80 \mathrm{~mL}$ of 5 vol.\% Triton X100 (Sigma-Aldrich) in deionized water; the final pH value was adjusted to 3.0 with $\mathrm{HCl}$ (Panreac $35 \%$ ). The closed autoclave was heated to $453 \mathrm{~K}$ in an oven for 48 hours, after which it was cooled to ambient temperature. A yellow 
powder was obtained, which was separated by centrifugation, washed six times with distilled water and finally dried in air at $333 \mathrm{~K}$. CdS was synthesized in a similar way from $20 \mathrm{mM} \mathrm{Cd}\left(\mathrm{CH}_{3} \mathrm{COO}\right)_{2} \cdot 2 \mathrm{H}_{2} \mathrm{O}$ (Aldrich 99.99+\%) and $80 \mathrm{mM}$ thiourea (Aldrich 99\%) in deionized water at $453 \mathrm{~K}$ during $48 \mathrm{~h}$. A high thiourea:Cd ratio was chosen, following literature indications [39], to facilitate obtaining only the hexagonal wurtzite phase.

The elemental composition of the obtained powder was measured with total reflection X-ray fluorescence (Rich \& Seifert TXRF EXTRA-II spectrometer). BET specific surfaces were measured with a Micromeritics system on samples preoutgassed at $423 \mathrm{~K}$ during $4 \mathrm{~h}$. X-ray diffractograms were collected using a Philips X'Pert Pro PANalytical diffractometer using $\mathrm{Cu}$ K $\alpha$ radiation $(\lambda=1.542 \AA$ ), and UV-vis-NIR diffuse reflectance spectra were obtained with a Cary- Varian 5000 spectrometer, using Spectralon ${ }^{\circledR}$ as reference material. From the diffractograms the lattice parameter values were obtained by fitting to computed patterns using the Powdercell program [40].

XPS measurements were carried out with a SPECS spectrometer using a $400 \mathrm{~W}$ monochromatized Al Ka X-ray source (photon energy = $1486 \mathrm{eV}$ ), a PHOIBOS 150 hemispherical analyzer with 9-channel detector and a FG 15/40 electron flood gun for charge compensation. Spectra were acquired with SpecsLab2 software and analyzed with XPSpeak software [41]. In this analysis the XPS peaks were referred to the adventitious $C(1 \mathrm{~s})$ signal, assumed to have binding energy $E_{B}=250 \mathrm{eV}$, and the atomic sensitivity factors were taken from the tables provided by the spectrometer manufacturer.

\subsection{Photocatalytic tests}

For both sulphides the photocatalytic activity was studied by following at room temperature the oxidation of formic acid $(1.5 \mathrm{mM})$ at its natural pH (=2.5 initially) in an aqueous suspension. The experiments were carried out in a homemade thermostated Pyrex glass reactor, containing $40 \mathrm{mg}$ of sulphide powder in $80 \mathrm{ml}$ of suspension, which was naturally aerated through magnetic stirring under ambient atmosphere. After keeping the stirred suspension in the dark during $30 \mathrm{~min}$ to ensure a stable $\mathrm{HCOOH}$ concentration in the solution (adsorption was anyway small: only $1.2 \%$ of the initially dissolved amount, as judged by the analyzed $\mathrm{HCOOH}$ concentrations), the mixture was irradiated from above through a Pyrex window using an ozone-free $450 \mathrm{~W}$ Xenon lamp from Spectratech provided with a collimating condenser lens, a water filter (to eliminate thermal IR components) and, when so desired, one of a collection of bandpass optical filters from Andover Corporation transmitting a wavelength interval of FWHM width around $50 \mathrm{~nm}$. The incident light intensity was previously checked with a Newport 842-PE radiometer. The changes in the formic acid concentration were monitored by sampling periodically a small volume $(1.5 \mathrm{ml})$ of the suspension, which was filtered with a PTFE $0.45 \mu \mathrm{m}$ filter to separate the solid, and measuring the $\mathrm{HCOOH}$ concentration in the liquid with a UV-vis Shimadzu UV-2100 spectrometer though its absorbance at $\lambda=205 \mathrm{~nm}$. The photocorrosion of the photocatalyst during a reaction run was checked by filtering the solid from the suspension after the reaction and analyzing with ICP-OES both metal and sulphur in the liquid.

\section{Results and discussion}


The $\mathrm{Sn}: \mathrm{S}$ ratio of the synthesized tin disulphide, as measured by TXRF, is identical within $1 \%$ to the nominal stoichiometry 1:2; its specific surface area is $\mathrm{S}_{\mathrm{BET}}=36 \mathrm{~m}^{2} / \mathrm{g}$. Its X-ray diffractogram, shown in Fig. 1(a), evidences a good crystallinity in the product, with all peaks in agreement with the hexagonal $2 \mathrm{H}$ phase of $\mathrm{SnS}_{2}$ [42] (JCPDS card no. 230677). Peak fitting gives cell parameters $a=3.649 \AA, c=5.899 \AA$ in reasonable agreement with experimental literature values ( $a=3.647 \AA$, c=5.901 $\AA$ ) [43]. Using Scherrer's formula an average cystallite size of $23 \mathrm{~nm}$ is obtained from the width of the XRD $\left(\begin{array}{lll}1 & 0 & 1\end{array}\right)$ peak (at $2 \theta=32.4^{\circ}$ ). As shown by the XRD pattern in Fig. 2(a) the CdS specimen synthesized, which has specific surface area $\mathrm{S}_{\mathrm{BET}}=8 \mathrm{~m}^{2} / \mathrm{g}$ (similar to that found for another hydrothermally prepared CdS photocatalyst [44]), has also good crystallinity; its diffractogram corresponds to the hexagonal (wurtzite) polymorph of this sulphide, with measured unit cell parameters $a=4.135 \AA$ and $c=6.753 \AA$ (reported values are $a=4.132 \AA$ and $c=6.734$ $\AA$ [45]). The presence of the cubic (sphalerite) form can be excluded in view of the absence of its characteristic $\left(\begin{array}{lll}2 & 0 & 0\end{array}\right)$ reflection occurring at $2 \theta \approx 30.6^{\circ}$.

The UV-vis diffuse reflectance spectrum of $\mathrm{SnS}_{2}$ was measured and converted into the absorption spectrum, shown in Fig. 1(b), using the Kubelka-Munk transform of the reflectance $R\left(K M=(1-R)^{2} / 2 R\right)$ [46]. The figure shows a clear absorption edge starting at $\lambda \approx 550 \mathrm{~nm}$, corresponding to a photon energy of $2.25 \mathrm{eV}$, i.e. close to the bandgap of the material. For the CdS synthesized material, the spectrum in Fig. 2(b) displays an absorption edge also around $\lambda \approx 550$ $\mathrm{nm}$, a bit higher in this case than the value $\mathrm{A} \approx 500 \mathrm{~nm}$ corresponding to the reported value of its bandgap $\left(\mathrm{E}_{\mathrm{g}} \approx 2.4 \mathrm{eV}\right.$ ) [44] due perhaps to some disorder effects.

\subsection{Photocatalytic activity tests}

Fig. 3 shows the results obtained with $\mathrm{SnS}_{2}$ and $\mathrm{CdS}$ in the photocatalytic degradation of formic acid under irradiation with the full light spectrum of the Xenon lamp, of which only the thermal IR component was suppressed with the water filter. The total intensity of light incident on the suspension surface was about $115 \mathrm{~mW} / \mathrm{cm}^{2}$. The figure shows the concentration decay, and also that no significant decay occurred when keeping the $\mathrm{SnS}_{2}$ suspension in the dark (an analogous result, not shown, was obtained for the suspension with CdS in the dark); likewise, no significant decay took place in the irradiation experiment without photocatalyst (data not shown). It is inferred that the degradation of aqueous formic acid occurs as a photocatalytic process, and that both $\mathrm{SnS}_{2}$ and CdS can efficiently promote it.

In principle, several processes can conceivably produce the $\mathrm{HCOOH}$ decay: plain total photo-oxidation (1), partial photo-oxidation to oxalic acid (2) and two different decompositions without involvement of $\mathrm{O}_{2}(3$ and 4$)$ :

$\mathrm{HCOOH}+1 / 2 \mathrm{O}_{2} \rightarrow \mathrm{CO}_{2}+\mathrm{H}_{2} \mathrm{O}$

$2 \mathrm{HCOOH}+1 / 2 \mathrm{O}_{2} \rightarrow \mathrm{HOOCCOOH}+\mathrm{H}_{2} \mathrm{O}$

$\mathrm{HCOOH} \rightarrow \mathrm{CO}_{2}+\mathrm{H}_{2}$

$\mathrm{HCOOH} \rightarrow \mathrm{CO}+\mathrm{H}_{2} \mathrm{O}$

Process (3) can probably be discarded, since visible light-driven photocatalytic $\mathrm{H}_{2}$ production on main group sulphides with consumption of an organic sacrificial agent normally requires the presence of a metallic co-catalyst like Pt. 
Although to these authors' knowledge this has not yet been shown for $\mathrm{SnS}_{2}$, it has been verified in the case of the relatively similar $\ln _{2} S_{3}$ [47]. Process (2) is also not the relevant one here, since during the photoreaction the pH rises until reaching a value $>4$ at the end of the process, when near full $\mathrm{HCOOH}$ degradation is achieved; this excludes a significant buildup of oxalic acid. Since verification of CO production could not be carried out here, as gas phase analysis could not be performed in this experimental setup, process (4) cannot be excluded strictly; but it seems less likely than the other remaining candidate process (1), as dehydration process (4) is normally typical of acid catalysis (as opposed to process (3), typical of more basic materials or of transition metal-mediated redox processes), and the acidity of $\mathrm{SnS}_{2}$ is expected to be low. We will assume thus that process (1) is the main (if not exclusive) degradation path. In any case, the objective of the present work is not the mechanistic study of the HCOOH photodecomposition reaction, but the verification of the spectral response capability and stability of $\mathrm{SnS}_{2}$ as photocatalyst, for which we use as test molecule a simple acid the possible degradation products of which do not absorb the photoreaction driving light.

The effective reaction rate constant $(k)$ of the photocatalytic reaction is calculated assuming a pseudo-first order kinetic law, which is usually the case for the photocatalytic processes when the pollutant is in the millimolar concentration range:

$\ln \left(C_{0} / C\right)=k \cdot t$

By fitting semilog plots (not shown) this constant was determined to be $k=0.021 \mathrm{~min}^{-1}$ for $\mathrm{SnS}_{2}$ and $\mathrm{k}=0.0088 \mathrm{~min}^{-1}$ for $\mathrm{CdS}$. Thus the $\mathrm{SnS}_{2}$ nanoparticles used here can be significantly more active in photocatalyzing the degradation of aqueous formic acid than the typically used CdS photocatalyst material. It must be noted, however, that a rigorous activity comparison would need an evaluation of the total amount of light absorbed by each semiconductor; this is rather difficult to carry out as this amount is affected not only by the reactor geometry but also by the optical dispersion of the radiation used which is a function of the dimensions and equivalent refractive index of the nanoparticle aggregates. The specific surface area, higher for our $\mathrm{SnS}_{2}$ than for the $\mathrm{CdS}$ specimen used, may have also an effect, although it may be recalled that higher SBET values are frequently accompanied also, due to a lower crystallinity degree, by higher amounts of defects which may affect negatively the photocatalytic performance. Besides, a significant number of the XRD peaks of the CdS specimen show somewhat larger widths than those of the $\mathrm{SnS}_{2}$ sample, implying smaller crystalline domains; the fact that its $\mathrm{S}_{\mathrm{BET}}$ value is however smaller suggests that the $\mathrm{CdS}$ sample has a higher degree of crystallite agglomeration, with a larger number of grain boundaries which may also contribute to electron-hole recombination. A thorough study of all these effects falls outside the scope of the present work.

The dependence between photocatalytic activity and incident light wavelength was checked for the $\mathrm{SnS}_{2}$ material using a series of bandpass filters. The different decays observed for different values of $\lambda$ (the wavelength of maximum transmission of the filter) are shown in Fig. 4(a). Each curve was obtained using a fresh, unused photocatalyst portion. The $k$ values obtained from the corresponding semilog plots are represented in Fig. 4(b) against the wavelength $\lambda$ of the filter used. In this last figure it can be seen that the photocatalytic action spectrum follows the absorption profile of 
the material, evidencing that all absorbed photon energies are active in the photoreaction. The incident light intensity on the top of the suspension when using these filters was measured with the radiometer and found to be more or less constant in the wavelength range used, around $5 \mathrm{~mW} / \mathrm{cm}^{2}$; from this value an equivalent quantum yield (ratio between molecules transformed per second and total photon flux incident on the liquid surface) of $\eta \approx 2.1 \%$ at $500 \mathrm{~nm}$ could be determined. The fact that in the experiment without filters the $k$ value was higher than in presence of them by a factor smaller than what could be expected from the total light intensities may be due to a proportionally higher fraction of electron-hole pairs being lost by recombination under higher light intensity conditions.

\subsection{Photostability tests}

The stability of a sulphide photocatalyst is always a matter of concern, so it is important to investigate it and verify the reproducibility of results upon prolonged use of the material. Indeed sulphide photocatalysts usually display activity loss during photooxidation reactions due to corrosion, which occurs because photogenerated holes or $\mathrm{OH}$ radicals derived from them, as well as peroxide or superoxide ions resulting from the electron uptake by $\mathrm{O}_{2}$, can react not only with dissolved organic matter, but also with the surface sulphide ions giving oxidation products (ultimately sulphate ions) and dissolution of the solid. To check this in our work, one same portion of $\mathrm{SnS}_{2}$ was recycled five times in the photocatalytic formic acid degradation reaction using the full unfiltered light of the Xe lamp, restoring the formic acid concentration after each $5 \mathrm{~h}$ run by addition of the pure compound to the solution. The $\mathrm{HCOOH}$ concentration was measured before and after each $5 \mathrm{~h}$ irradiation (no aliquots were taken in the intermediate times, to minimize solid losses). The result of this test is displayed in Fig. 5, which shows that even after the fifth cycle the photocatalyst continues being highly active, as it is seen in the figure comparing the formic acid concentration remaining after the first run (0.7\%) with the value for the fifth run (6.2\%). When the same experiment was carried out using CdS the loss of activity was more important, since the concentration of formic acid remaining in solution after $5 \mathrm{~h}$ of irradiation increased from $21 \%$ in the first run to $47 \%$ in the fifth one. After the last of these runs the $\mathrm{SnS}_{2}$ sample was tested again for photoactivity; the initial apparent constant was then $k=0.0175 \mathrm{~min}^{-1}$, i.e. lower by $\approx 29 \%$ than that measured for the fresh sample. In the case of $\mathrm{CdS}$, the same experiment gave for the rate constant at the last run a value $k=$ $0.0041 \mathrm{~min}^{-1}$, evidencing a decrease from the initial one (by 53\%) which is significantly higher than for $\mathrm{SnS}_{2}$.

In a related experiment, after each 5-h run the solid was separated from the liquid by decanting and centrifugation and the total content of metal and sulphur in the solution was analyzed, while the recovered solid was added to a fresh formic acid solution and the irradiation cycle was carried out again on this suspension; this was repeated several times. The accumulated amount of each element that had passed into solution after each run is represented in Fig. 6 . It shows that $\mathrm{SnS}_{2}$ is photocorroded much less than $\mathrm{CdS}$ under these oxidative conditions, in spite of its higher specific surface.

Noting that, although only very small amounts of $\mathrm{SnS}_{2}$ components have been dissolved, there is some decrease in the photocatalytic activity, an XPS analysis of the $\mathrm{SnS}_{2}$ surface was undertaken to check if there is any relevant change in its composition or redox state. Table 1 and Fig. 7 show the results of this analysis, comparing the $\mathrm{SnS}_{2}$ sample before and after performing the cycle tests depicted in Fig. 5 . The fresh sample displays a $\mathrm{Sn}(3 \mathrm{~d})$ doublet with $3 \mathrm{~d}_{5 / 2}$ binding energy $(487.3 \mathrm{eV})$ close to the value $(487.0 \mathrm{eV})$ reported in the literature for $\mathrm{SnS}_{2}[48]$. The overall $(\{\mathrm{O}+\mathrm{S}\} /\{\mathrm{Sn}\})$ ratio is 
however lower than expected for a $\mathrm{Sn}^{4+}$ compound, suggesting that some reduction of $\mathrm{Sn}$ has occurred at the surface before or during the exposure to the X-ray beam. This is not manifested by the observation of new peaks at the $\mathrm{Sn}(3 \mathrm{~d})$ peaks, but it must be noted that the difference in $\mathrm{E}_{\mathrm{B}}$ between $\mathrm{SnS}$ and $\mathrm{SnS}_{2}$ is small, and even has opposite sign to that between $\mathrm{SnO}$ and $\mathrm{SnO}_{2}$ [48]; therefore the said partial reduction (of $\mathrm{Sn}^{4+}$ to $\mathrm{Sn}^{2+}$, presumably) does not necessarily have to be discernible as a distinct peak in the $\mathrm{Sn}(3 \mathrm{~d})$ spectrum, especially in the presence of some oxygen. On the contrary, the used photocatalyst displays a small new component at $E_{B}=488.5 \mathrm{eV}$. $E_{B}$ values above $488 \mathrm{eV}$ are infrequent in Sn compounds, but have been found in scarcely covalent salts like $\mathrm{SnF}_{4}$ [49]; thus it may be ascribed to $\mathrm{Sn}$ bound to a ligand with lower electron donating ability than oxide or sulphide.

In the $S(2 p)$ region the fresh photocatalyst displays a single doublet with $E_{B}=162.3 \mathrm{eV}$, a value approaching that presented by other layered heavy metal disulphides like $\mathrm{MoS}_{2}$ [50] or $\mathrm{WS}_{2}$ [51]. On the other hand the used photocatalyst shows in the $S(2 p)$ region a new small contribution having $E B=163.6 \mathrm{eV}$ in the $2 p_{3 / 2}$ peak. This increase suggests some oxidation but is certainly too small to allow an assignment to $\mathrm{SO}_{4}{ }^{2-}$ or $\mathrm{SO}_{3}{ }^{2-}$ species; it is rather similar to that of $\mathrm{CS}_{2}$ [52], suggesting the possible formation of a bond with formic acid, while the $\mathrm{C}(1 \mathrm{~s})$ shows a significant increase in a peak at $E_{B} \approx 286.8 \mathrm{eV}$ that may be due to $\mathrm{C}-\mathrm{O}$ or $\mathrm{C}-\mathrm{S}$ bond containing species. Although a definitive interpretation of these changes cannot be given here, a moderate degree of modification of the surface is evidenced which might imply the formation of C-S bonds (due e.g. to trapping of holes at surface $\mathrm{S}$ atoms followed by attack to dissolved formate ions) and a change of the ligands of some surface $\mathrm{Sn}$ atoms, changing the photocatalytic properties of the $\mathrm{SnS}_{2}$ material even if no dissolution of its components takes place. Further studies will be required to fully clarify this point.

The effect of these changes on the photocatalytic activity is however moderate, and smaller than for CdS, as shown by the results in Fig. 5. This higher stability observed for $\mathrm{SnS}_{2}$ may well be due to the cohesive energy of the sulphide lattice, which is expected to be higher for the $\mathrm{SnS}_{2}$ structure thanks to the higher charge and higher number of M-S bonds on the cation (Sn cations are octahedrally coordinated while Cd ones are tetrahedral in CdS), leading to a higher Madelung lattice energy. Thus the $\mathrm{S}^{-}$(radical) and/or $\mathrm{Cd}^{+}$species that may transiently form at the surface of $\mathrm{CdS}$ upon irradiation due to charge carrier trapping (or, in the first case, to attack by $\mathrm{O}_{2}{ }^{-}$or related species formed from the dissolved $\mathrm{O}_{2}$ ) may be less strongly retained by the rest of the solid and detach from it to become finally dissolved species.

\section{Conclusions}

It was possible to synthesize pure $\mathrm{SnS}_{2}$ nanoparticles simply via hydrothermal reaction between $\mathrm{SnCl}_{4} \cdot 5 \mathrm{H}_{2} \mathrm{O}$ and thiourea in a 5 vol\% Triton aqueous solution. The synthesized $\mathrm{SnS}_{2}$ material exhibited higher photocatalytic activity in degrading aqueous formic acid as well as higher resistance to photocorrosion than the much studied CdS. We also provide evidence, not given before, that the full range of photons absorbed by $\mathrm{SnS}_{2}$ (up to $\lambda \approx 600 \mathrm{~nm}$, i.e. all those with energy close to or above its $2.2 \mathrm{eV}$ bandgap) is active to promote the photocatalysis process. These aspects, together with the low toxicity and the relatively high natural abundance of $\mathrm{Sn}$ in comparison to $\mathrm{Cd}$, make $\mathrm{SnS}_{2}$ a good candidate 
alternative to CdS for a range of photon absorption-related applications.

\section{Acknowledgements}

This work was carried out with support from projects GENESIS-FV of the Consolider-Ingenio programme (project no. CSD2006-0004) and FOTOMAT of the Plan Nacional de Materiales (project no. MAT2009-14625-C03), both financed by the Spanish Plan Nacional de Investigación, and from programme NUMANCIA-2 (code no. S2009ENE-1477) financed by the Comunidad de Madrid. R.L. thanks also the CSIC for a PhD grant of its I3P programme, under which this research was undertaken.

\section{References}

[1] M. Mrowetz, E. Selli, J. Photochem. Photobiol. A: Chem. 180 (2006) 15-22.

[2] T. Bak, J. Nowotny, M. Rekas, C.C. Sorrell, Int. J. Hydrogen Energy 27 (2002) 991-1022.

[3] See e.g. several reviews in, M. Anpo, P.V. Kamat (Eds.), Environmentally Benign Catalysts-Applications of Titanium Oxide-Based Photocatalysts, Springer, New York, 2010: (a) N. Serpone, A.V. Emeline, V.N. Kuznetsov, V.K. Ryabchuk, pp. 35-112.; (b) J. Zhou, X.S. Zhao, pp. 235-252.; (c) T. Ono, T. Tsubota, pp. 253-276.; (d) M. Fernández-García, A. Martínez-Arias, J.C. Conesa, pp. 277-300.; (e) M. Takeuchi, M. Anpo, pp. 301-320.

[4] P. Maruthamuthu, K. Gurunathan, E. Subramanian, M. Ashokkumar, Bull. Chem. Soc. Jpn. 64 (1991) 1933-1937.

[5] M. Hara, T. Kondo, M. Komoda, S. Ikeda, K. Shinohara, A. Tanaka, J.N. Kondo, K. Domen, Chem. Commun. 3 (1998) 357-358.

[6] Y. Yu, W.Y. Huang, F.P. Du, L.L. Ma, Mater. Sci. Forum 475-479 (2005) 3531-3534.

[7] A. Kudo, K. Ueda, H. Kato, I. Mikami, Catal. Lett. 53 (1998) 229-230.

[8] Y. Hosogi, Y. Shimodaira, H. Kato, H. Kobayashi, A. Kudo, Chem. Mater. 20 (2008) 1299-1307.

[9] Z.G. Zou, J.H. Ye, H. Arakawa, Mater. Res. Bull. 36 (2001) 1185-1193.

[10] G. Hitoki, A. Ishikawa, T. Takata, J.N. Kondo, M. Hara, K. Domen, Chem. Lett. 7 (2002) 736-737.

[11] A. Kasahara, K. Nukumizu, T. Takata, J.N. Kondo, M. Hara, H. Kobayashi, K. Domen, J. Phys. Chem. B 107 (2003) 791-797.

[12] K. Maeda, K. Teramura, T. Takata, M. Hara, N. Saito, K. Toda, Y. Inoue, H. Kobayashi, K. Domen, J. Phys. Chem. B 109 (2005) 20504-20510.

[13] T. Aruga, K. Domen, S. Naito, T. Onishi, K. Tamaru, Chem. Lett. 3 (1983) 321-324.

[14] T.R. Thurston, J.P. Wilcoxon, J. Phys. Chem. B 103 (1999) 11-17. 
[15] Y. Bessekhouad, M. Mohammedi, M. Trari, Sol. Energy Mater. Sol. Cells 73 (2002) 339-350.

[16] Y. He, D. Di, G. Xiao, W. Chen, Y. Chen, M. Sun, H. Huang, X. Fu, J. Phys. Chem. C 113 (2009) 5254-5262.

[17] W. Wang, W. Zhu, L. Zhang, Res. Chem. Intermed. 25 (2009) 761-767.

[18] X. Di, S.K. Kansal, W. Deng, Sep. Purif. Technol. 68 (2009) 61-64.

[19] G.F. Lin, J.W. Zheng, R. Xu, J. Phys. Chem. C 112 (2008) 7363-7370.

[20] A.F. Wells, Structural Inorganic Chemistry, Clarendon Press, Oxford, 1975. [21] R.S. Mitchell, Y. Fujiki, Y. Ishizawa, Nature 247 (1974) 537.

[22] D.L. Greenaway, R. Nitsche, J. Phys. Chem. Solids 26 (1965) 1445.

[23] M.J. Powell, E.A. Marseglia, W.Y. Liang, J. Phys. C: Solid State Phys. 11 (1978) 895; R. Bacewicz, B. Palosz, W. Palosz, S. Gierlotka, Solid State Commun. 54 (1985) 283.

[24] S. Mandalidis, J.A. Kalomiros, K. Kambas, A.N. Anagnostopoulos, J. Mater. Sci. 31 (1996) 5975-5978.

[25] S.K. Panda, A. Antonakos, E. Liarokapis, S. Bhattacharya, S. Chaudhuri, Mater. Res. Bull. 42 (2007) 576-583.

[26] E. Lifshitz, Z. Cben, L. Bykov, J. Phys. Chem. 97 (1993) 238-242.

[27] G.B. Dubrovskii, Phys. Solid State 40 (1998) 1557-1562.

[28] G.B. Dubrovskii, A.I. Shelykh, Phys. Solid State 40 (1998) 1295-1296.

[29] N.G. Deshpande, A.A. Sagade, Y.G. Gudage, C.D. Lokhande, J. Alloys Compd. 436 (2007) 421-426.

[30] Y.C. Zhang, Z.N. Du, W. Li, M. Zhang, Appl. Catal. B 95 (2010) 153-159; Y.C. Zhang, Z.N. Du, K.W. Li, M. Zhang, Sep. Purif. Technol. 81 (2011) 101-107.

[31] Y. Lei, S. Song, W. Fan, Y. Xing, H. Zhang, J. Phys. Chem. C 113 (2009) 1280-1285.

[32] W.M. Du, D.H. Deng, Z.T. Han, W. Xiao, C. Bian, X.F. Qian, Cryst. Eng. Commun. 13 (2011) 2071-2076.

[33] H.Y. He, J.F. Huang, L.Y. Cao, J.R. Wu, Z. He, L. Luo, J. Optoel. Adv. Mater. 9 (2007) 3781-3784.

[34] C. Yang, W. Wang, Z. Shan, F. Huang, J. Solid State Chem. 182 (2009) 807-812.

[35] Y.C. Zhang, Z.N. Du, W. Li, M. Zhang, D.D. Dyonisiou, ACS Appl. Mater. Interfaces 3 (2011) 1528-1537.

[36] O. Husser, H. von Känel, F. Levy, Helv. Phys. Acta 57 (1984) 519-520.

[37] A. Katty, B. Fotouhi, O. Gorochov, J. Electrochem. Soc. 131 (1984) 2806-2810; B. Fotouhi, A. Katty, O. Gorochov, C. R. Acad. Sci. Paris 303 (Series II) (1986) 1001-1004.

[38] L. Sharp, D. Soltz, B.A. Parkinson, Cryst. Growth Des. 6 (2006) 1523-1527.

[39] N. Bao, L. Shen, T. Takata, K. Domen, A. Gupta, K. Yanagisawa, C.A. Grimes, J. Phys. Chem. C 111 (2007) 17527.

[40] Powder cell program v.2.4. <http://www.bam.de/de/service/publikationen/powder cell.html>.

[41] Xpspeak program v. 4.1. <http://www.uksaf.org/xpspeak41.zip>. 
[42] F.A.S. Al-Alamy, A.A. Balchin, M. White, J. Mater. Sci. 12 (1977) 2037-2042.

[43] R.S. Mitchell, Y. Fujiki, Y. Ishizawa, Nature 247 (1974) 537-538.

[44] Y. Li, J. Du, S. Peng, D. Xie, G. Lu, S. Li, Int. J. Hydrogen Energy 33 (2008) 2007.

[45] M. Ikeda, H. Wada, T. Wada, T. Hirao, J. Cryst. Growth 135 (1994) 476-480.

[46] G. Dupuis, M. Menu, Appl. Phys. A: Mater. Sci. Process. 83 (2006) 469-474.

[47] X. Fu, X. Wang, Z. Chen, Z. Zhang, Z. Li, D.Y.C. Leung, L. Wu, X. Fu, Appl. Catal. B: Environ. 95 (2010) 393.

[48] W.E. Morgan, J.R. Van Wazer, J. Phys. Chem. 77 (1973) 964.

[49] D. Shuttleworth, J. Phys. Chem. 84 (1980) 1629.

[50] Z. Shuxian, W.K. Hall, G. Ertl, H. Knözinger, J. Catal. 100 (1986) 167.

[51] V.I. Zaikovskii, A.P. Shepelin, V.A. Burmistrov, A.N.Y. Startsev, I. Yermakov, React. Kinet. Catal. Lett. 25 (1984) 17.

[52] C.D. Wagner, J.A. Taylor, J. Electron Spectrosc. Relat. Phenom. 28 (1982) 211. 


\section{Table 1}

Binding energies and atomic ratios (referred to the total amount of Sn detected) measured in the XPS spectra of fresh and photoreaction-used $\mathrm{SnS}_{2}$.

\begin{tabular}{llllll}
\hline XPS peak & Fresh & & \multicolumn{2}{l}{ After photo reaction } \\
\cline { 2 - 3 } \cline { 5 - 6 } \cline { 5 - 5 } & $E_{\mathrm{B}}(\mathrm{eV})$ & $\mathrm{X} / \mathrm{Sn}$ at. ratio & & $E_{\mathrm{B}}(\mathrm{eV})$ & $\mathrm{X} / \mathrm{Sn}$ at. ratio \\
\hline $\mathrm{Sn}\left(3 \mathrm{~d}_{5 / 2}\right)$ & 487.3 & 1.0 & 487.2 & 0.87 \\
& & & 488.5 & 0.13 \\
$\mathrm{~S}\left(2 \mathrm{p}_{3 / 2}\right)$ & 162.3 & 1.3 & 162.2 & 1.3 \\
& & & 163.6 & 0.09 \\
$\mathrm{O}(1 \mathrm{~s})$ & 533.3 & 0.13 & 533.3 & 0.31 \\
& 531.7 & 0.09 & 531.4 & 0.05 \\
$\mathrm{C}(1 \mathrm{~s})$ & 536.1 & 0.02 & & \\
& 285.0 & 0.14 & 285.0 & 0.13 \\
& 286.9 & 0.22 & 286.8 & 0.50 \\
\hline
\end{tabular}




\section{Figure captions}

Fig. 1. (a) Powder XRD diagram (indicating the Miller indices of the hexagonal phase reflections) and (b) UV-vis-NIR absorption spectrum (given as Kubelka-Munk transform of the diffuse reflectance) of hydrothermally synthesized $\mathrm{SnS}_{2}$

Fig. 2. (a) Powder XRD diagram (indicating the Miller indices of the hexagonal phase reflections) and (b) UV-vis-NIR absorption spectrum (given as Kubelka-Munk transform of the diffuse reflectance) of hydrothermally synthesized CdS.

Fig. 3. Decay of formic acid concentration upon irradiation with the full light spectrum of the Xe lamp in suspensions of $\mathrm{SnS}_{2}$ or CdS, measured from the absorbance of the solution at $\lambda=205 \mathrm{~nm}$. The decay curve in the dark $\left(\right.$ with $\left.\mathrm{SnS}_{2}\right)$ is also given.

Fig. 4. (a) $\mathrm{HCOOH}$ concentration decay in an aqueous suspension of $\mathrm{SnS}_{2}$, irradiated through bandpass filters of different wavelengths $\lambda$; the decay observed with unfiltered light is also shown. (b) Effective first-order rate constant $k$, measured from the initial slope of the decay curves obtained with the different filters, compared with the Vis-NIR spectrum (given as negative logarithm of the diffuse reflectance $\mathrm{R}$ ) of the $\mathrm{SnS}_{2}$ material used.

Fig. 5. Total $\mathrm{HCOOH}$ concentration decay in five successive $5 \mathrm{~h}$ irradiation runs (adding to the suspension a new portion of solid $\mathrm{HCOOH}$ at the start of each run) carried out with one same $\mathrm{SnS}_{2}$ portion.

Fig. 6. Plot of the total accumulated amount of photocatalyst constituents gone into the solution due to photocorrosion during five successive $5 \mathrm{~h}$ photocatalysis runs on fresh $\mathrm{HCOOH}$ solutions, with intermediate separation of the solid, comparing the results obtained with $\mathrm{SnS}_{2}$ and $\mathrm{CdS}$.

Fig. 7. XPS spectra of the $\mathrm{SnS}_{2}$ sample obtained before and after 5 cycles of irradiation with full Xe lamp light spectrum in $\mathrm{HCOOH}$ suspension. 
Fig. 1
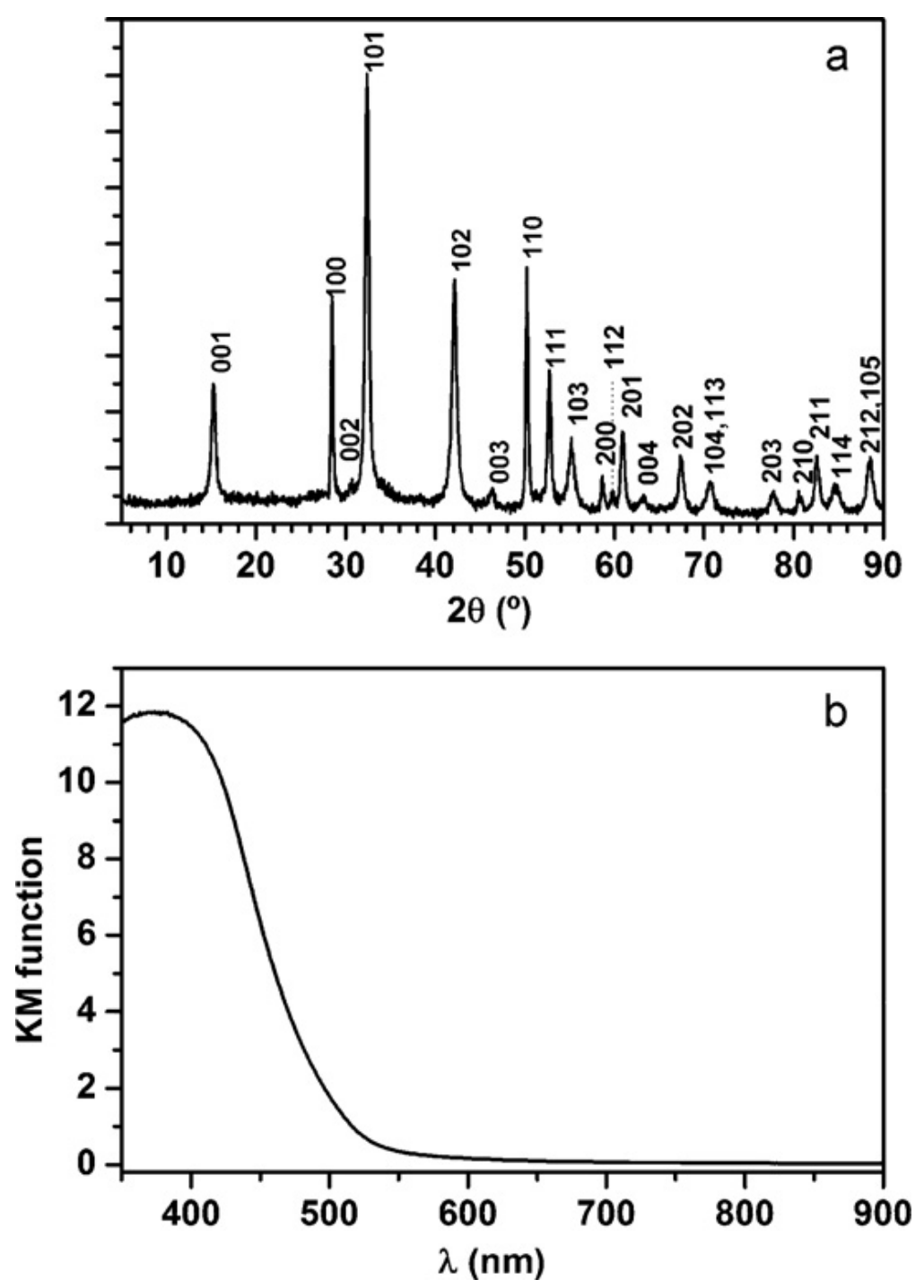
Fig. 2
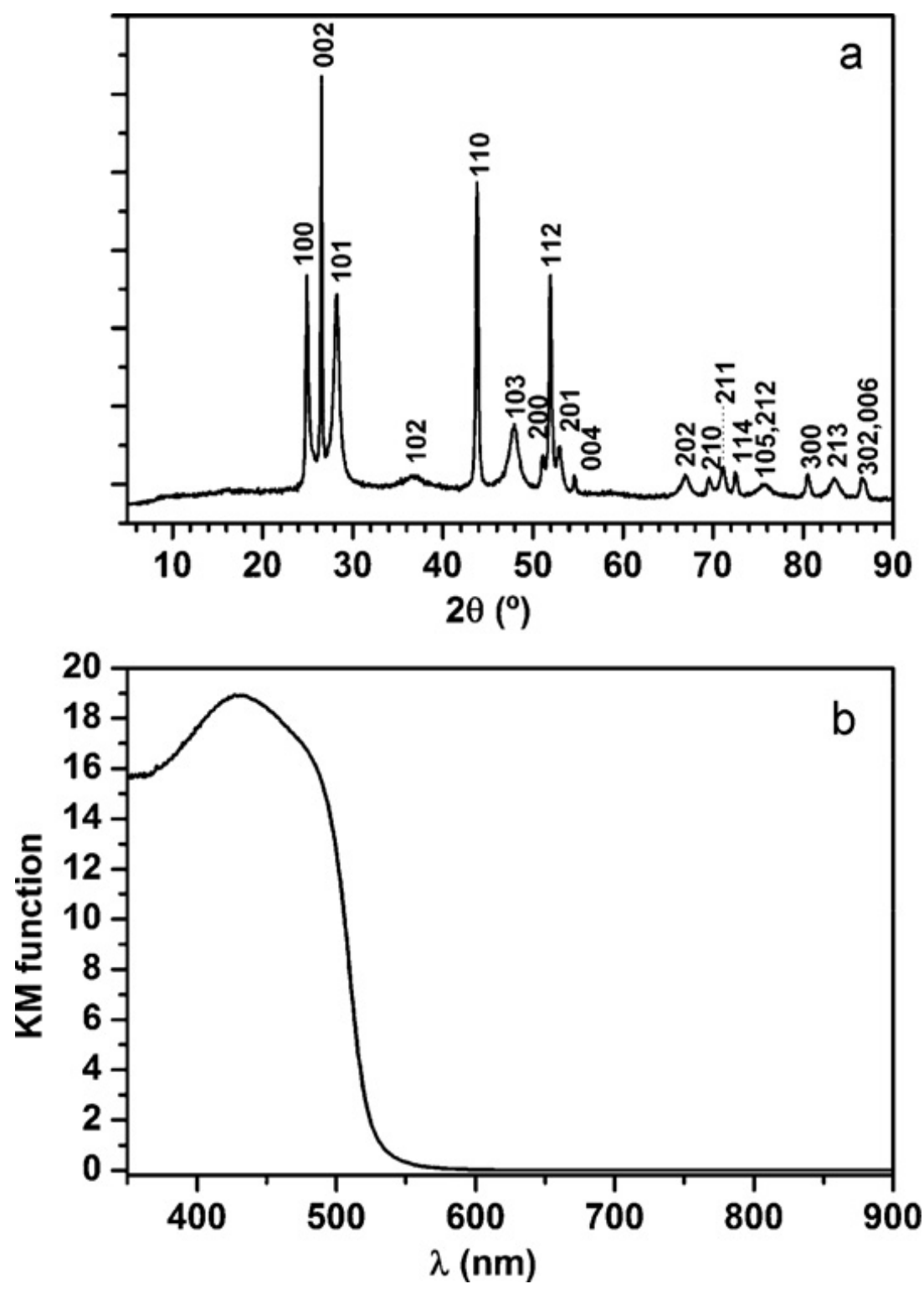
Fig. 3

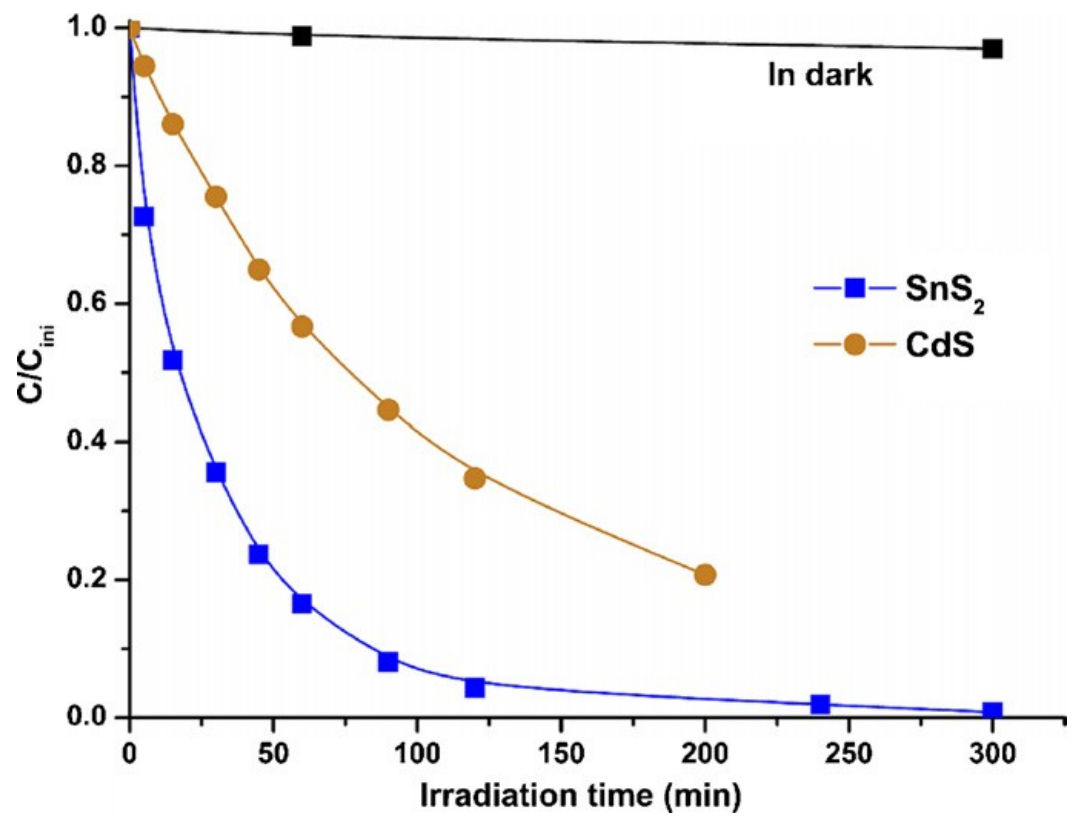


Fig. 4
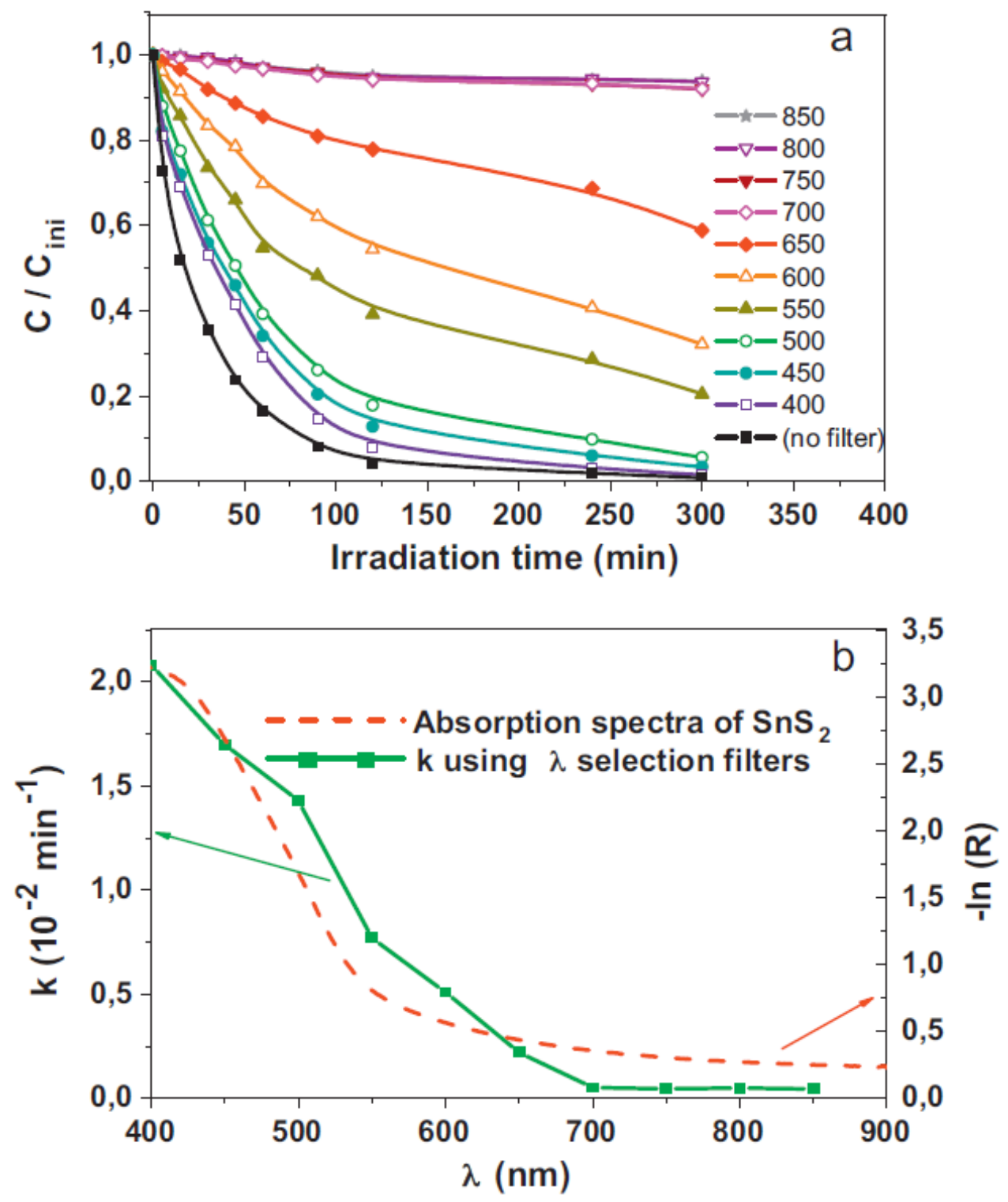
Fig. 5

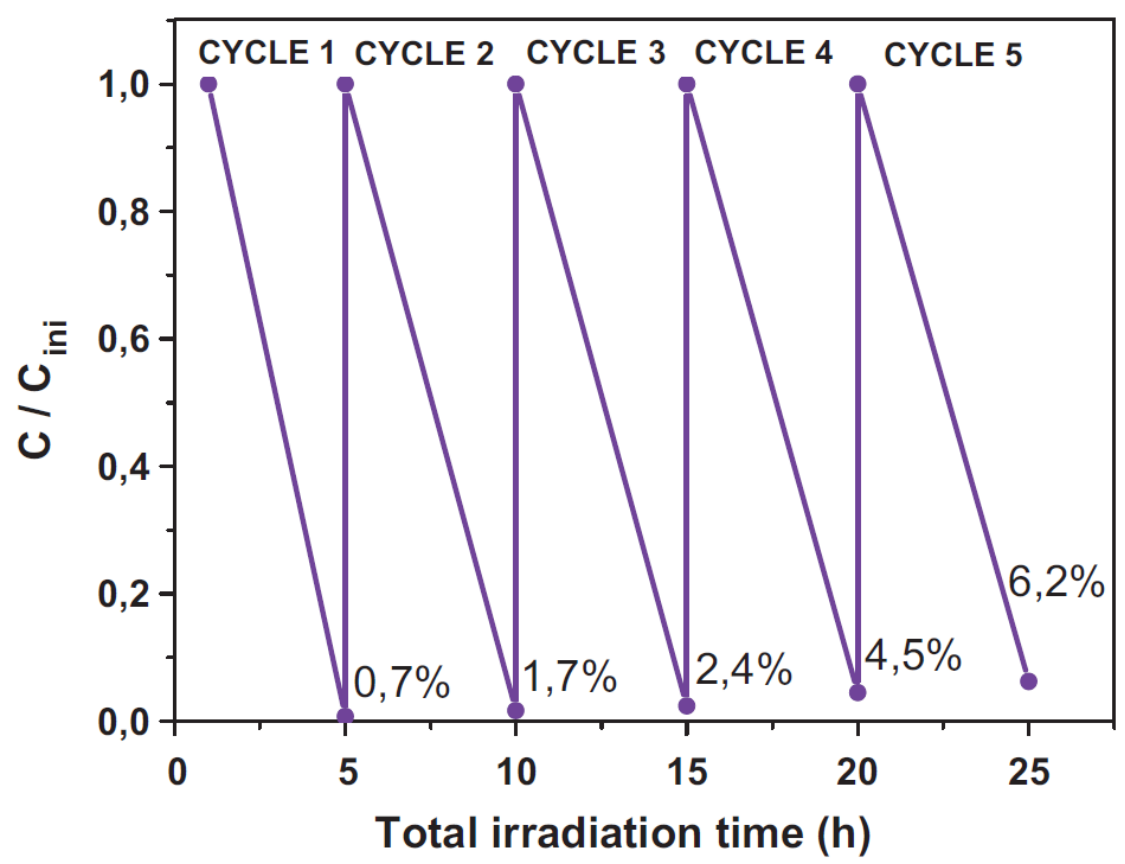


Fig. 6

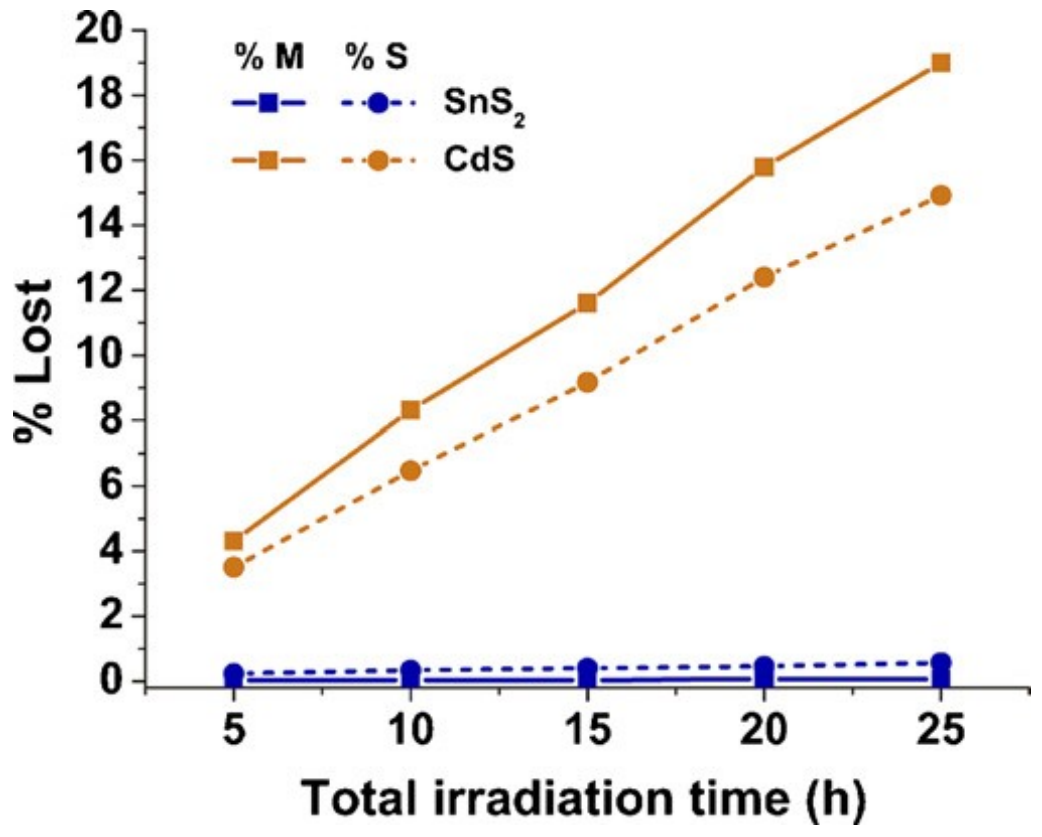


Fig. 7
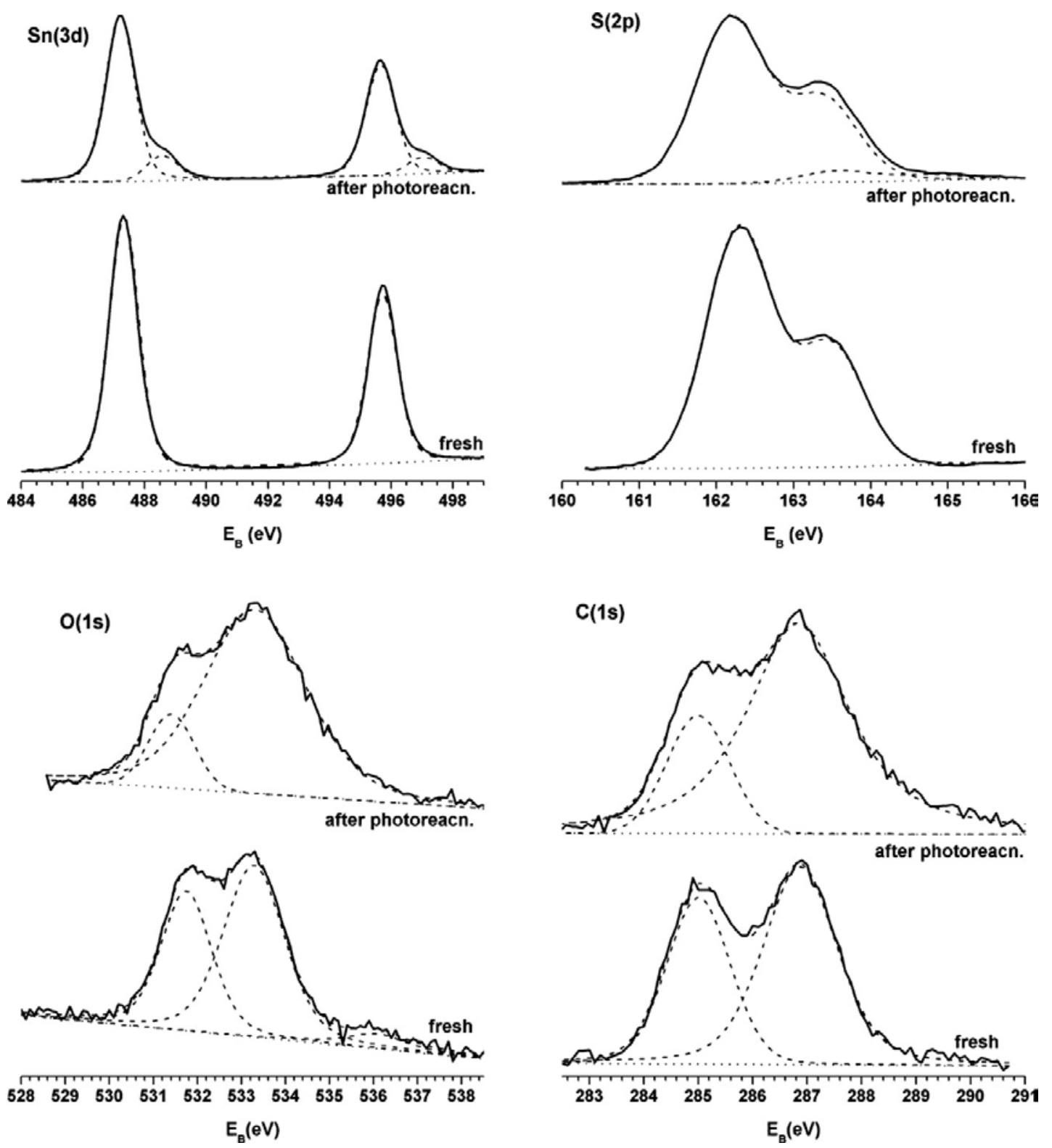